Colloids and Surfaces

A: Physicochemical and Engineering Aspects 113 (1996) 155-163
COLLOIDS

AND SURFACES

\title{
Interactions between alum and organics in coagulation
}

\author{
Chihpin Huang *, Hueiling Shiu \\ Institute of Environmental Engineering, National Chiao Tung University 75 Po-ai street, Hsinchu, Taiwan 30039 , \\ People's Republic of China
}

Received 3 November 1995; accepted 15 January 1996

\begin{abstract}
The coagulation-sedimentation process, i.e. a major pretreatment for filtration, has the potential to remove organic contaminants. However, interactions between coagulants and organics in the absence of suspended solids have only received limited attention. This study aims to model alum-organics' interactions corresponding to the behavior of organics during coagulation. Two typical organic materials, humic acid and salicylic acid, are investigated. Experimental results indicate that the removal of organics by coagulation is directly related to the molecular weight. The interaction of alum with humic acid involves complexation, charge neutralization, precipitation and adsorption. The coagulation of salicylic acid with alum arises from adsorption and entrapment. Results of this study confirm a stoichiometric relationship between the initial concentrations of humic acid and optimal alum dosages.
\end{abstract}

Keywords: Alum; Coagulation; Humic acid; Organic contaminants; Salicylic acid; Water treatment

\section{Introduction}

Sources of organics in the public water supply comprise not only natural organic matter but also industrial, stock and domestic wastewaters. Organic matter in a water source is undesirable, especially with respect to generating disinfection by-products. The coagulation-sedimentation process, i.e. a major pretreatment for filtration, has the potential to remove organic contaminants.

Humic substances are commonly found in soil, sediments and natural waters. The behavior of humic substances in the coagulation and flocculation processes has been widely investigated. Hall and Packham [1] felt that humic acid and fulvic acid removal from water by iron and aluminum coagulants could be regarded as a process of chemical precipitation forming insoluble basic

\footnotetext{
* Corresponding author.
}

aluminum/iron humates rather than coagulation. This variety of precipitates may be soluble or insoluble, depending on the coagulant dose [2]. A stoichiometry between humics' concentration and optimum dosage has been also confirmed [2-4].

Dempsey et al. $[5,6]$ have stated that coagulation of humic substances with coagulants can be achieved through charge neutralization and adsorption. Dempsey [7] has concluded that adsorption is the most important mechanism for fulvic acid removal over the entire $\mathrm{pH}$ range. However, Van Benschoten and Edzwald [8] have indicated that the role of complexation of aluminum and fulvic acid in coagulation is significant. In addition, coprecipitation during organics' coagulation has been discussed $[9,10]$. Studies involving the domain of specific organics' removal by coagulation have found that these organic compounds with a low molecular weight are less easily eliminated than humic substances [11-13]. 
Notably, preformed flocs built from the coagulation of kaolinite suspension by alum/iron salts have good adsorption characteristics for organic matter [14-16]. These results are not only valuable in water treatment but are meaningful for organic removal by coagulation.

The most representative mechanisms for the destabilization of colloids include electric-doublelayer compression, adsorption and charge neutralization, enmeshment, and interparticle bridging. However, most previous work has focused on the application of those mechanisms to describe the behavior of suspended particles coagulated with chemicals. Whether the mechanisms involved in the coagulation of organics are similar to those for mineral particles still remains unclear. So far, the interaction between coagulants and organics with different molecular weight (MW) ranges in the absence of suspended solids has only received limited attention. Therefore, in this study, the characteristics of organic coagulation by alum are more thoroughly explored and the mechanism of organic substances' removal by alum coagulation is also examined. Humic acid and salicylic acid are chosen here as model organics due to the differences in their molecular weights. Humic acid is naturally widespread with an $\mathrm{MW}$ of a few hundred to 1000000 . Salicylic acid is a common aromatic acid in natural water and is a strong chelating agent, like fulvic acid [7].

\section{Materials and methods}

Humic acid was obtained from the commercial sodium humate (Aldrich, USA) with composition C: $51.37 \%, \mathrm{H}: 4.19 \%, \mathrm{~N}: 0.75 \%$, as indicated by Mazet [3]. Salicylic acid (analytical grade) was obtained from the Hayashi Co. (Japan). Stock solutions of the coagulant were prepared by dissolving aluminum sulfate (alum; $\mathrm{Al}_{2}\left(\mathrm{SO}_{4}\right)_{3} \cdot 18 \mathrm{H}_{2} \mathrm{O}$ Merck) in deionized water.

A synthetic sample was prepared to contain a desired concentration of humic acid. Nonpurgeable dissolved organic carbon (NPDOC) in the synthetic sample was measured by means of a TOC analyzer with UV/persulfate oxidation (Dohrmann DC-180, USA). The synthetic water alkalinity was created by using $100 \mathrm{mg} 1^{-1}$ $\mathrm{NaHCO}_{3}$. The initial ionic strength of water was controlled at $10^{-2} \mathrm{M}$. Therefore, $\mathrm{NaClO}_{4}$ was also added to the synthetic water to compensate for a deficit in ionic strength provided by the alkalinity. This study was in two parts. In the first part, a series of jar tests was performed in 11 beakers at room temperature. Next, according to the direction of the jar-test results, further experiments were designed to investigate the relationship between the initial concentrations of organics and optimal alum dosages, as well as organics' adsorption by aluminum hydroxide precipitates.

In the jar tests, the coagulant was added to the beaker containing the synthetic water and the $\mathrm{pH}$ was immediately adjusted to a given value with $\mathrm{NaOH}$. Rapid mixing $\left(150 \mathrm{rev} \mathrm{min}^{-1}\right)$ for $3 \mathrm{~min}$ was followed by $20 \mathrm{~min}$ of slow mixing ( $20 \mathrm{rev}$ $\min ^{-1}$ ) and $2 \mathrm{~h}$ of quiescent settling. The $\mathrm{pH}$ values were recorded at the end of the settling period, after the completion of which the supernatants were analyzed by means of a UV analyzer $(1 \mathrm{~cm}$ cell; Hitachi model U-3210, Japan) at a wavelength of $254 \mathrm{~nm}$ for humic acid or $231 \mathrm{~nm}$ for salicylic acid. Next, the supernatant samples were passed through a $0.45 \mu \mathrm{m}$ filter (cellulose nitrate, Whatman) and again analyzed by UV spectrophotometry. The material, as collected by the $0.45 \mu \mathrm{m}$ filter, was operationally defined as a "precipitate" in this study.

In the adsorption experiment, the alum precipitates generated by undergoing rapid mixing for 30 min were used as adsorbents for the organics. A given concentration of organic compound was added to the alum suspension for the adsorption. Finally, the suspension was filtered and the filtrate was analyzed by means of the UV analyzer after $24 \mathrm{~h}$ at $25^{\circ} \mathrm{C}$.

A comparison of sequential dosing with single dosing was performed to determine the effects of different dosing methods on the organics' removal. A $25 \mathrm{ml}$ amount of alum reagent was prepared with a suitable concentration and this was then divided into five parts. Each of the $5 \mathrm{ml}$ portions of the alum reagent was transferred to the synthetic sample after the mixing-settling process had been completed in each time interval. For each time 
interval, a supernatant sample was collected for UV absorbance measurements.

\section{Results and discussion}

Suspended solids are absent in our synthetic waters, and the removal of dissolved organic matter occurs with a phase change in which precipitates are produced.

\subsection{Elementary jar testing}

Jar testing has been performed using alum to coagulate humic acid and salicylic acid. Residual organics after jar settling are shown in Fig. 1 as a function of $\mathrm{pH}$ at a given dosage. The upper curves

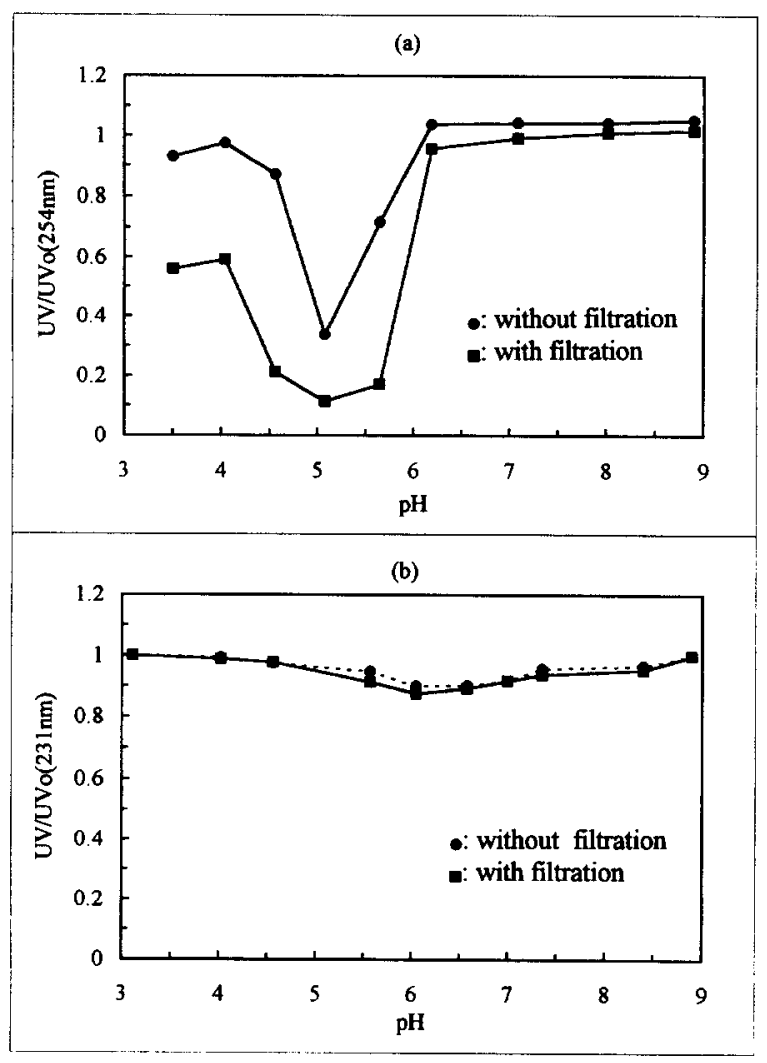

Fig. 1. Residual organics after jar mixing-settling as a function of $\mathrm{pH}$ at given dosages. (a) Humic acid: initial concentration, $4 \mathrm{mg} \mathrm{NPDOC} 1^{-1}$; alum, $0.8 \mathrm{mg} \mathrm{Al} \mathrm{^{-1 }}$. (b) Salicylic acid:

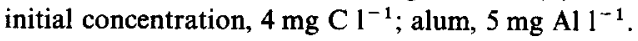

in Figs. 1(a) and 1(b), representing organics remaining after coagulation and settling, are termed "settled curves" in the following description. The lower curves in Figs. 1(a) and 1(b), indicating organics remaining after coagulation, settling and membrane filtration, are defined here as "filtered curves". The difference between the two curves is the quantity of precipitate that fails to settle. Experimental results indicate that optimal $\mathrm{pH}$ values for humic acid and salicylic acid removal are different (equivalent to 5 and 6, respectively). Generally, the ionization of carboxyl groups $\left(\mathrm{p} K_{\mathrm{a}} \approx 4.5\right.$ [17]) leads to a situation in which humic acid possesses a negative charge. Under the $0.8 \mathrm{mg} \mathrm{Al} 1^{-1}$ condition, the positively charged mononuclear or polynuclear species of $\mathrm{Al}$ (III) is predominant at $\mathrm{pH} 5$ after hydrolysis. Such Al(III) species induce a complexation reaction with humic acid, the latter functioning as a strong organic ligand for $\mathrm{Al}(\mathrm{III})$. The latter species can also neutralize the negatively charged sites on humic acid, which subsequently forms aluminum humate. Fig. 1(b) also indicates that an insignificant removal occurs with salicylic acid by alum coagulation, even with a relatively higher dosage than that applied for the humic acid removal as shown in Fig. 1(a).

The ratios of residual and original UV absorbances are shown in Fig. 2 as a function of alum dosage. This figure clearly indicates that the optimal dosage for humic acid is about $1.0 \mathrm{mg} \mathrm{A} 11^{-1}$, which corresponds to $90 \%$ removal. Aluminum humate may be water-soluble or water-insoluble, depending on its molecular size. As the alum dosage is increased, aluminum humate may aggregate and form precipitates after jar mixing. These results also indicate that restabilization occurs in the settled curve of humic acid, as shown in Fig. 2(a). This implies that the destabilization of humic acid by alum cannot be attributed to the compression of the electric double layer but to charge neutralization. As the dosage is increased, the fraction of aluminum hydroxide precipitated as the hydrolyzed $\mathrm{Al}$ (III) species increases. Therefore, more humic acid or aluminum humate can be adsorbed onto the aluminum hydroxide precipitates, causing removal by jar settling or membrane filtering. As the alum dosage increases 


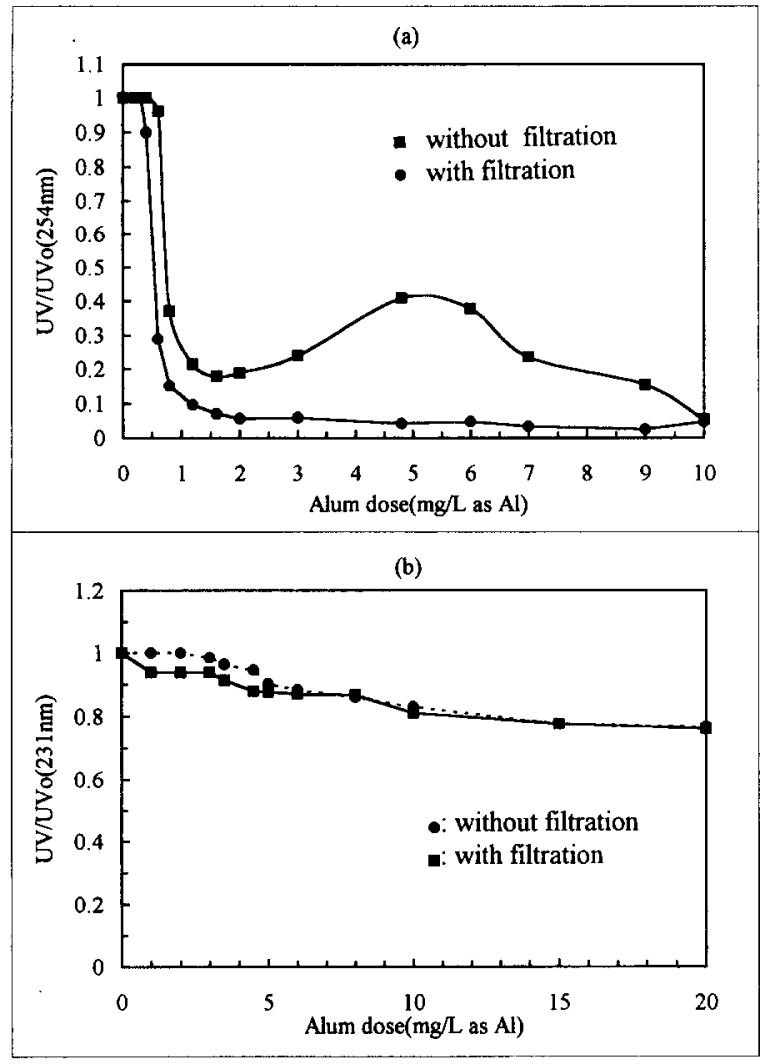

Fig. 2. Residual organics after jar mixing-settling as a function of dosage at a given $\mathrm{pH}$. (a) Humic acid: initial concentration, $4 \mathrm{mg} \mathrm{NPDOC} \mathrm{l}^{-1}$; $\mathrm{pH}$ 5. (b) Salicylic acid: initial concentration, $4 \mathrm{mg} \mathrm{Cl}^{-1}$; pH 6 .

over a certain level at which a large quantity of aluminum hydroxide precipitate is produced, the major mechanism of humic acid removal by alum coagulation can be expected to shift from complexation-charge neutralization-precipitation to adsorption. The result in Fig. 2(b) shows that justifying an optimal dosage for salicylic acid is relatively difficult. The difference between the settled curve and the filtered curve appears only at an alum dosage of less than $6 \mathrm{mg} \mathrm{Al} 1^{-1}$. A higher dosage of alum gives a settled curve that corresponds with the filtered curve. This phenomenon is discussed in the following section. Although the functional groups $(-\mathrm{COOH}$ and $-\mathrm{OH})$ of salicylic acid are similar to those of humic acid, the behavior of salicylic acid in alum coagulation is different from that of humics. It is postulated that the molecular weight of the organic compound is an important factor for organics' coagulation.

The stability of precipitates formed during jar tests has been evaluated by measuring the turbidities of the supernatant at three different settling times (Fig. 3). These results indicate that the turbidity increases with dosage when there is no settling. In addition, the turbidity decreases as the settling time increases. As shown in Fig. 3(a), precipitates are very stable when the alum dosage is

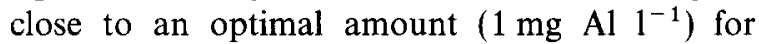
humic acid. Besides, the occurrence of restabilization shown in Fig. 2(a) imparts a rise in turbidity at $2 \mathrm{~h}$ settling in Fig. 3(a). A comparison with the blank test results (sample without organics), shown in Fig. 3(b), reveals that higher turbidity values are obtained in the sample containing humic acid

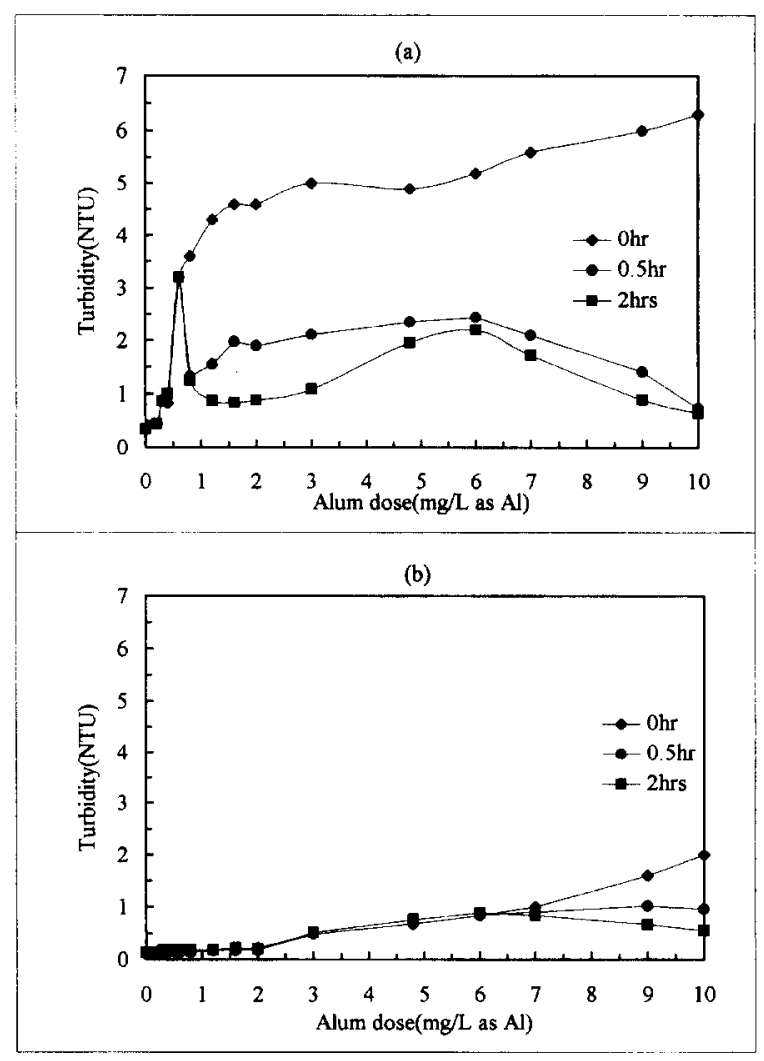

Fig. 3. Turbidity of the supernatant of three different settling times as a function of dosage at $\mathrm{pH} 5$. (a) With humic acid (initial concentration, $4 \mathrm{mg} \mathrm{NPDOC} 1^{-1}$ ); (b) without humic acid. 
for alum doses below $9 \mathrm{mg}^{-1}$. This indicates that precipitates not only result from $\mathrm{Al}(\mathrm{OH})_{3}(\mathrm{~s})$ adsorption but from complexation-charge neutralization in the alum coagulation with humic acid, since precipitates in blank tests can only be generated by the presence of aluminum hydroxide. However, such a distinction of turbidity between blank and organic water is absent for salicylic acid, as shown in Fig. 4. This implies that the floc formed during the alum coagulation is primarily a result of amorphous $\mathrm{Al}(\mathrm{OH})_{3}$, and is not a result of complexation. Although salicylic acid carries a negative charge $\left(\mathrm{p} K_{\mathrm{a} 1}=2.97\right)$ in natural water, due to the low molecular mass of salicylic acid $(M W=$ 138.12), it is still almost impossible to form an organic-Al(III) precipitate larger in size than $0.45 \mu \mathrm{m}$ by the complexation of salicylic acid with positively hydrolyzed $\mathrm{Al}$ (III) species.

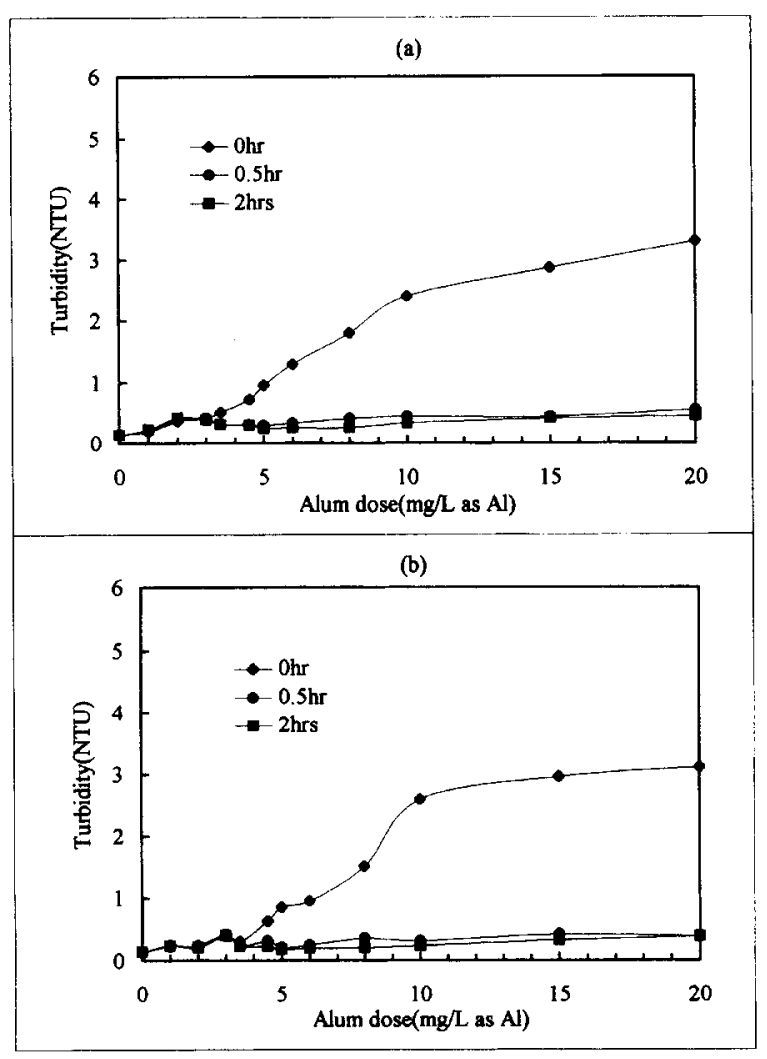

Fig. 4. Turbidity of the supernatant of three different settling times as a function of dosage at $\mathrm{pH} 6$. (a) With salicylic acid (initial concentration, $4 \mathrm{mg} \mathrm{C}^{-1}$ ); (b) without salicylic acid.
Figs. 5(a) and 5(b) show isoremoval lines for humic acid with the various alum dosages and $\mathrm{pH}$ values by jar mixing-settling and jar mixingsettling-filtering, respectively. There is a similar trend for three isoremoval lines $(60,80$, and $90 \%)$ in Fig. 5(a). It shows that the alum dosage required to reach an equivalent percentage of organic removal is decreased with a $\mathrm{pH}$ increase from 3 up to around 6.3, and then is increased if the $\mathrm{pH}$ is higher than 6.3. In addition, two regions of $80 \%$ removal of humic acid after the jar tests are found. These two regions consist of a low dosage of alum around $\mathrm{pH} 5$ and a high dosage of alum at $\mathrm{pH}$ above 6 . The first region mentioned is attributed to the occurrence of complexation-charge neutralization, and the second region covers the area in which the adsorption is a predominant mechanism for the destabilization of humic acid. It is also found that restabilization is absent at $\mathrm{pH}$ above 6 . Results in Fig. 5(b) indicate that a progressive increase occurs for optimal alum dosage at $\mathrm{pH} 6$ and 7 as compared to that at $\mathrm{pH} 5$. As salicylic acid removal is less than $25 \%$ under our experimental conditions, the results of its isoremoval lines are not discussed here.

\subsection{Relationship between initial concentrations of organics and optimum dosage}

Fig. 6 shows the residual concentrations of humic acid after jar mixing-settling-membrane filtering with various alum dosages at an optimal pH 5. Three initial concentrations of humic acid have been used to investigate the existence of a stoichiometric relationship between humic acid and alum dosage. This relationship at $\mathrm{pH} 5$ indicates that destablization can be achieved by charge neutralization resulting from a specific chemical interaction between positively charged aluminum species and negative functional groups of the humic acid, as shown in the inset graph.

\subsection{Adsorption study}

Fig. 7 shows the adsorption isotherms of salicylic acid by amorphous aluminum hydroxide flocs. The coagulation capacity of salicylic acid by jar mixingsettling-filtering is also included to make a com- 


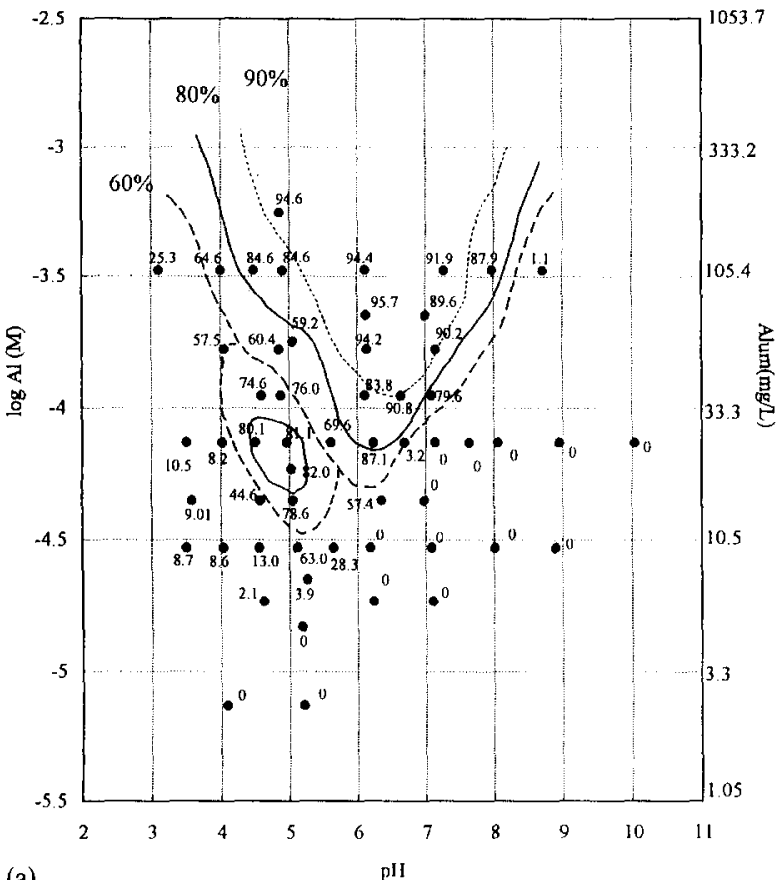

(a)

Fig. 5. Isoremoval lines of humic acid by (a) mixing
concentration of humic acid of $4 \mathrm{mg} \mathrm{NPDOC} \mathrm{I}^{-1}$.

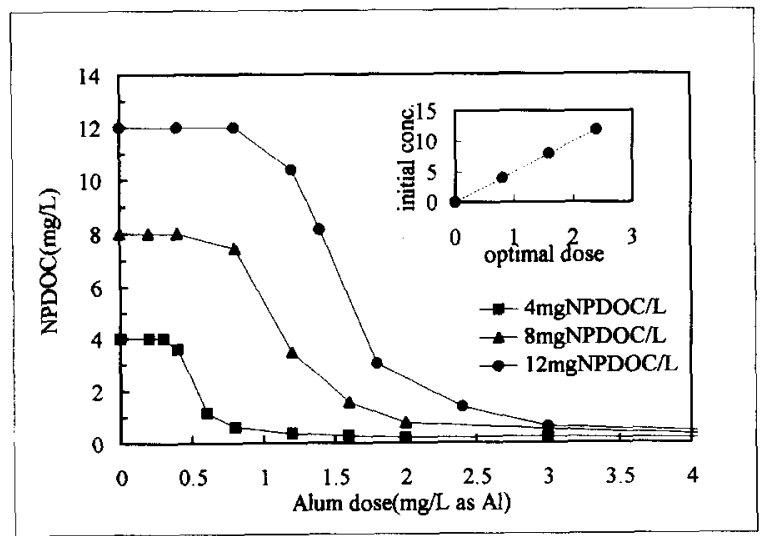

Fig. 6. Residual concentration of humic acid after mixing, settling, and membrane filtering with various alum dosages at $\mathbf{p H} 5$.

parison with the adsorption capacity. It is found that a linear correlation occurs with salicylic acid between the adsorption capacity and equilibrium concentration as well as the coagulation capacity and equilibrium (residual) concentration. Elzerman and Coates [18] indicated that the linear isotherm

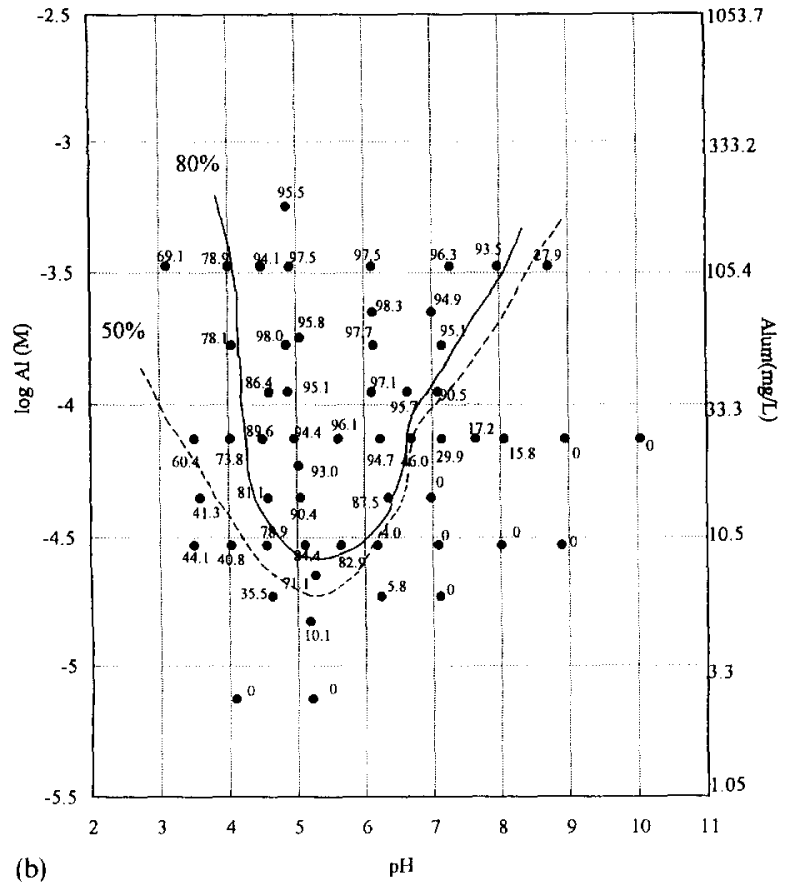

(b)

(b) mixing, settling, and membrane filtering with an initial

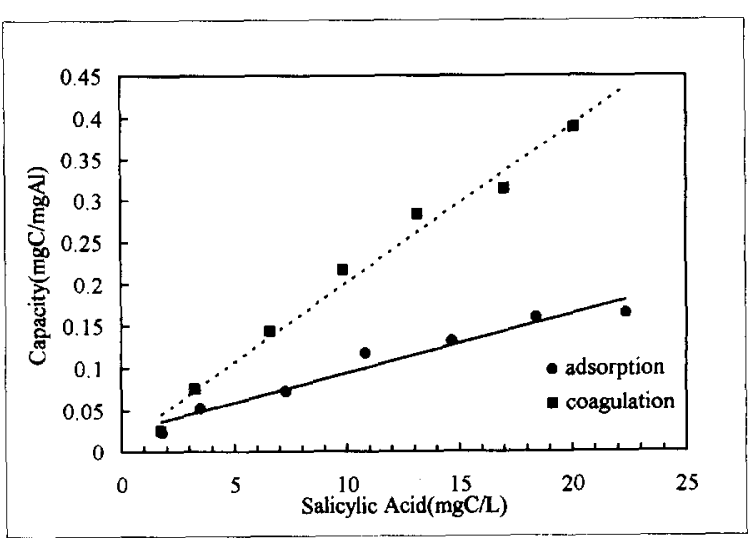

Fig. 7. Adsorption isotherms of salicylic acid by amorphous aluminum hydroxide precipitates (alum, $10 \mathrm{mg} \mathrm{Al}^{-1} ; \mathrm{pH} \mathrm{6}$ ).

can frequently describe the sorption of hydrophobic organic contaminants in soil and sediment environments. From Figs. 4 and 7, we can infer that the removal of low molecular weight organics such as salicylic acid by coagulation is attributed primarily to adsorption. This contradicts the work reported by Semmens and Ayers [11] in which 


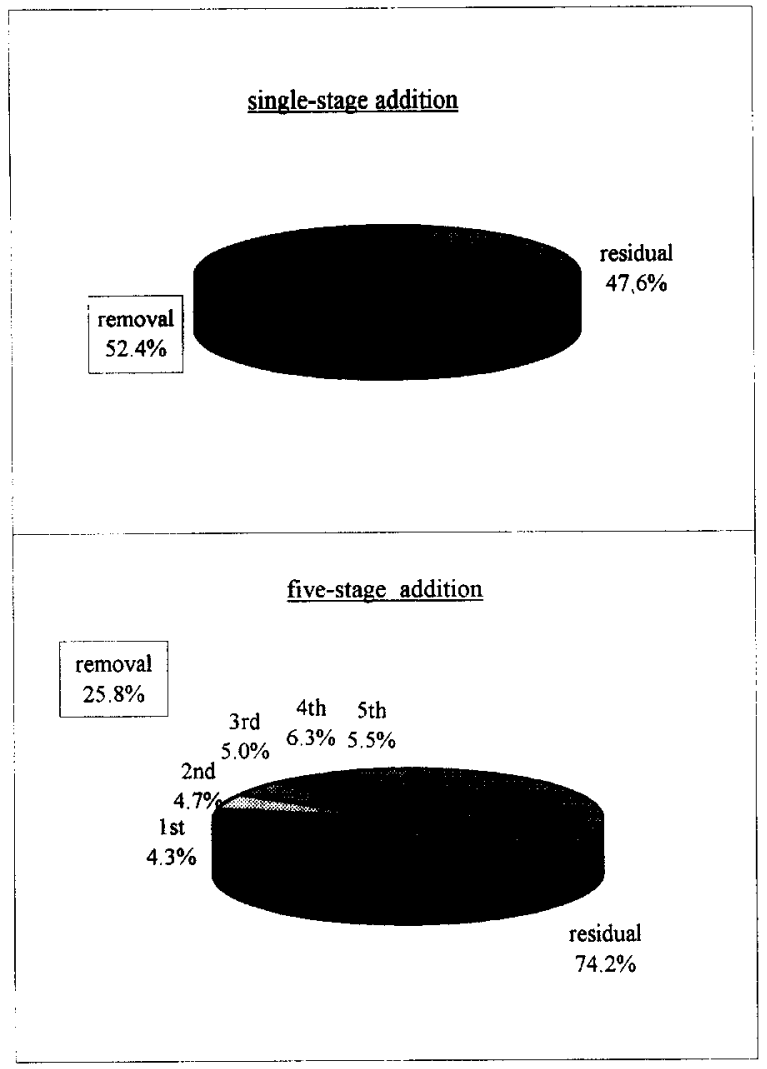

Fig. 8. Removal percentage of salicylic acid by mixing, settling, and membrane filtering with five-stage alum addition and a single alum addition while maintaining $\mathrm{pH} 6$ during rapid mixing (salicylic acid, $12 \mathrm{mg} \mathrm{C}^{-1}$; alum, $10 \mathrm{mg} \mathrm{Al}^{-1}$ ).

complexation is postulated as a major mechanism, not adsorption. The result also indicates that the difference in capacity between the adsorption and coagulation curves implies that the type of interaction between salicylic acid and alum is not only adsorption but also arises from mechanism. This is verified by the results in Fig. 8, as discussed in the following section.

\subsection{Sequential dosing tests}

Fig. 9 shows the removal percentage of humic acid by jar mixing-settling-membrane filtering with five-stage alum addition and a single alum addition while maintaining a fixed $\mathrm{pH}$ during the rapid mixing. The removal percentages of salicylic acid are presented in Fig. 8. These results indicate

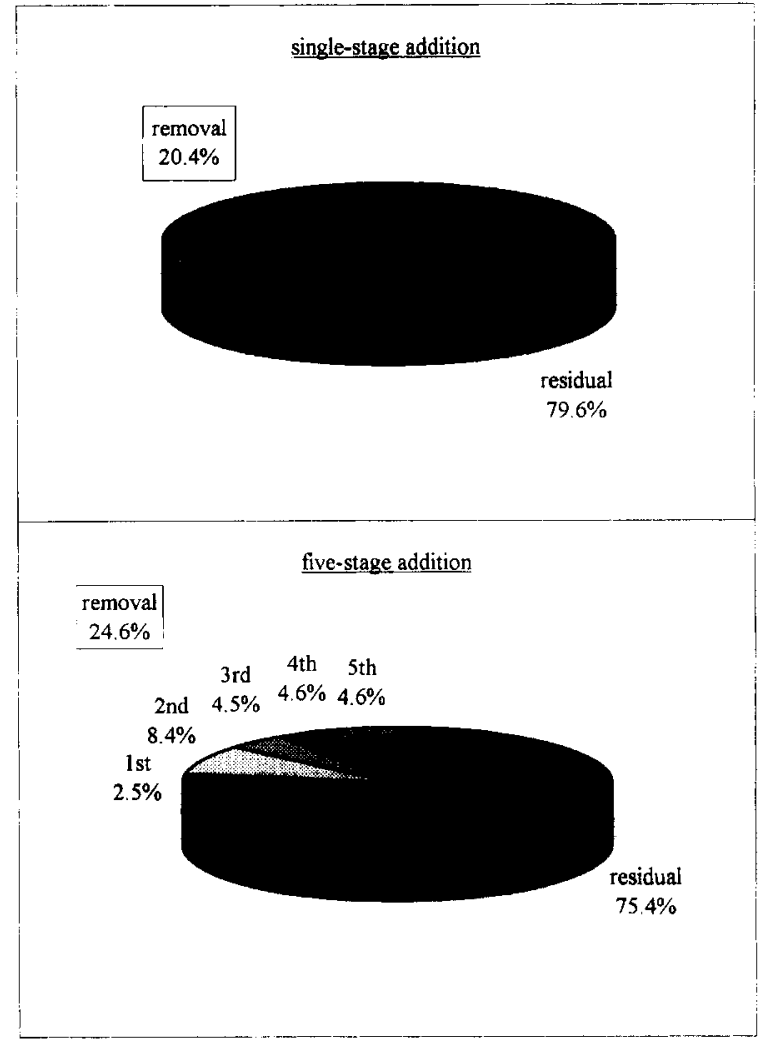

Fig. 9. Removal percentage of humic acid by mixing, settling, and membrane filtering with five-stage alum addition and a single alum addition at $\mathrm{pH} 7$ during rapid mixing (humic acid, $12 \mathrm{mg} \mathrm{NPDOC} 1^{-1}$; alum, $3.5 \mathrm{mg} \mathrm{Al}^{-1}$ ).

that a $52.4 \%$ removal of humic acid is achieved by single-stage alum addition compared to $25.8 \%$ removal by five-stage coagulation. Single-stage coagulation is obviously more favorable for removing humic acid than five-stage coagulation. However, this is in contrast to the case of salicylic acid, in which five-stage coagulation possesses a higher removal percentage than single-stage coagulation. The single-stage alum addition can momentarily produce $3.5 \mathrm{mg} \mathrm{Al}$ in 11 of the solution. Because a larger amount of $\mathrm{OH}^{-}$ions is required for adjusting the final $\mathrm{pH}$ to 7 in a single addition, it is favorable for the formation of aluminum hydroxide precipitates to adsorb humic acid. In the case of salicylic acid removal by five-stage coagulation, most of the $2 \mathrm{mg} \mathrm{Al} 1^{-1}$ addition at pH 6 in each stage can generate aluminum hydrox- 
ide precipitates, which can subsequently adsorb salicylic acid. Successive alum addition produces fresh $\mathrm{Al}(\mathrm{OH})_{3}$ precipitates which can become incorporated into old $\mathrm{Al}(\mathrm{OH})_{3}$ precipitates to form an aggregate, which is accompanied by the entrapping of salicylic acid into the aggregate. Actually, such an "entrapment" is present not only in sequential dosing but also in single alum dosing, so that sequential dosing enhances the effect.

\section{Conclusions}

The molecular weight of the organic compounds is an important factor in organics' removal by coagulation. The optimal $\mathrm{pH}$ values for humic acid and salicylic acid removal are different (equivalent to 5 and 6 , respectively). An insignificant removal occurs with salicylic acid by alum coagulation, even with a relatively higher dosage than that applied in humic acid removal. The major mechanisms of humic acid removal by alum coagulation involve complexation-charge neutralization-precipitation and adsorption. The predominant mechanisms of salicylic acid removal by coagulation include adsorption and entrapment. This conclusion may be described schematically, as in Fig. 10.

Precipitates are not only caused by $\mathrm{Al}(\mathrm{OH})_{3}(\mathrm{~s})$ adsorption, but by complexation-charge neutralization in alum coagulation with humic acid; precipitates are very stable when the alum dosage is close to the optimal amount for humic acid. For salicylic acid, the floc formed during alum coagulation is primarily a result of amorphous $\mathrm{Al}(\mathrm{OH})_{3}$ and does not result from complexation.

A stoichiometric relationship exists between the initial concentration of humic acid and optimal alum dosage. Also, a linear correlation occurs with salicylic acid between '1'213adsorption capacity and equilibrium concentration as well as coagulation capacity and equilibrium (residual) concentration. Single-stage coagulation is more favorable than five-stage coagulation for removing humic acid, but is less favorable for removing salicylic acid.

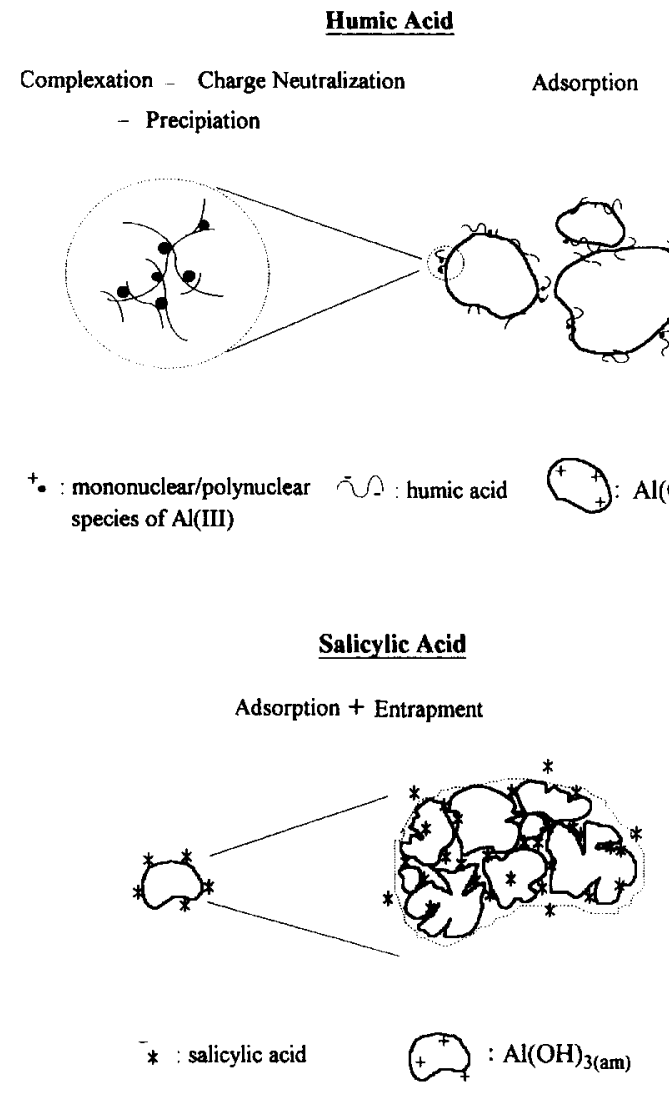

Fig. 10. Schematic diagram of mechanisms of alum coagulation: (a) humic acid; (b) salicylic acid.

\section{Acknowledgments}

The authors appreciate the financial support of the National Science Council, ROC, under award number NSC-83-0410-E-009-027 during this research. The valuable suggestions of the reviewers for improvements to the manuscript are greatly appreciated.

\section{References}

[1] E.S. Hall and R.F. Packham, J. Am. Water Works Assoc., 57 (1965) 1149.

[2] J.K. Edzwald, AIChE Symp. Ser. 19, 75 (1979) 54.

[3] G.A. Edwards and A. Amirtharajah, J. Am. Water Works Assoc., 77 (1985) 50.

[4] N. Narkis and M. Rebhun, J. Am. Water Works Assoc., 69 (1977) 325. 
[5] B.A. Dempsey, R.M. Ganho and C.R. O'Melia, J. Am. Water Works Assoc., 76 (1984) 141.

[6] B.A. Dempsey, H. Sheu and J. Mentink, J. Am. Water Works Assoc., 77 (1985) 74.

[7] B.A.Dempsey, in I.H. Suffet and P. MacCarthy (Eds.), Aquatic Humic Substances Influence on the Fate and Treatment of Pollutants, American Chem. Soc., Washington, DC, 1989, p. 409.

[8] J.E. Van Benschoten and J.K. Edzwald, Water Res., 24 (1990) 1527.

[9] T.R. Hundt and C.R. O'Melia, J. Am. Water Works Assoc., 80 (1988) 176.

[10] J.S. Randtke and C.P. Jepsen, J. Am. Water .Works Assoc., 73 (1982) 411.

[11] M.J. Semmens and K. Ayers, J. Am. Water Works Assoc., 77 (1985) 79.
[12] P. Th'ebault, J.M. Cases and F. Fiessinger, Water Res., 15 (1981) 183.

[13] E. Lefebvre and B. Legubbe, Water Res., 27 (1993) 433.

[14] F. Julien, B. Guerous and M. Mazet, Water Res., 28 (1994) 2567.

[15] M. Mazet and L. Angbo, Water Res., 24 (1990) 1509.

[16] G. Cathalifaund, M. Wais, M.T. Mossa and M. Mazet, Water Res., 27 (1993) 55.

[17] American Water Works Assoc. Committee Rep., J. Am. Water Works Assoc., 71 (1979) 588.

[18] A.W. Elzerman and J.T. Coates, in A.H. Ronald and S.J. Eisenreich (Eds.), Sources and Fates of Aquatic Pollutants, American Chemical Society, Washington, DC, 1987 , p. 263. 